\title{
Opinião
}

\section{RELATO DE UMA CRISE-EXPERIÊNCIA INTERIOR: UMA VIVÊNCIA MÍSTICA-ONTOLÓGICA}

Bernardo Melgaço da Silva (1)

"Existe em nós alguma coisa que pode existir sem nós e existirá depois de nós; alguma coisa que antes de nós não tinha história e que não se pode dizer como em nós entrou"

(Sir Thomas Browne)

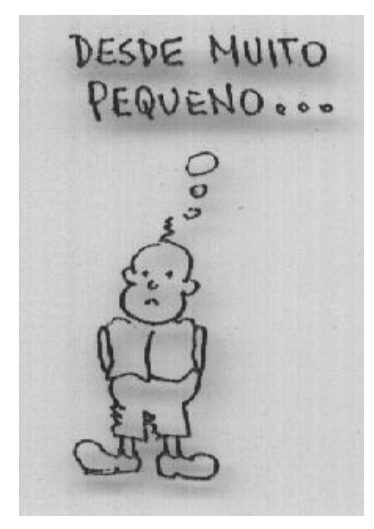

É importante, nesse momento, comentar sobre o início da minha busca espiritual nessa vida. A minha primeira necessidade de buscar uma resposta espiritual começou muito cedo, quando eu estava com 11 anos de idade. E foi uma experiência que me marcou profundamente. Naquela época eu vivia - com mais oito irmãos - sob os cuidados de uma madrasta que não me dava chance. Qualquer coisa que eu fizesse, e que ela interpretasse como algo de "errado", era motivo para um violento ataque (tapas e outras coisas mais) gratuito.

Eu sofria muito! Até que uma vez, na minha inocência de guri, ajoelhei-me no banheiro da minha casa e roguei ao Senhor-Deus para intervir naquela relação. O que se passou nos meses seguintes não me deixou dúvida de que minha súplica havia sido atendida. Inclusive, a minha madrasta havia sido avisada (na minha presença, por uma "entidade espiritual" que incorporava de vez em quando numa menina de 13 anos - vizinha nossa!) do que ocorreria caso ela não mudasse de comportamento em relação a mim. Os anos foram se passando e vários fenômenos espirituais iam me mostrando que "algo" existia também além das minhas capacidades humanas de entendimento e visão. 


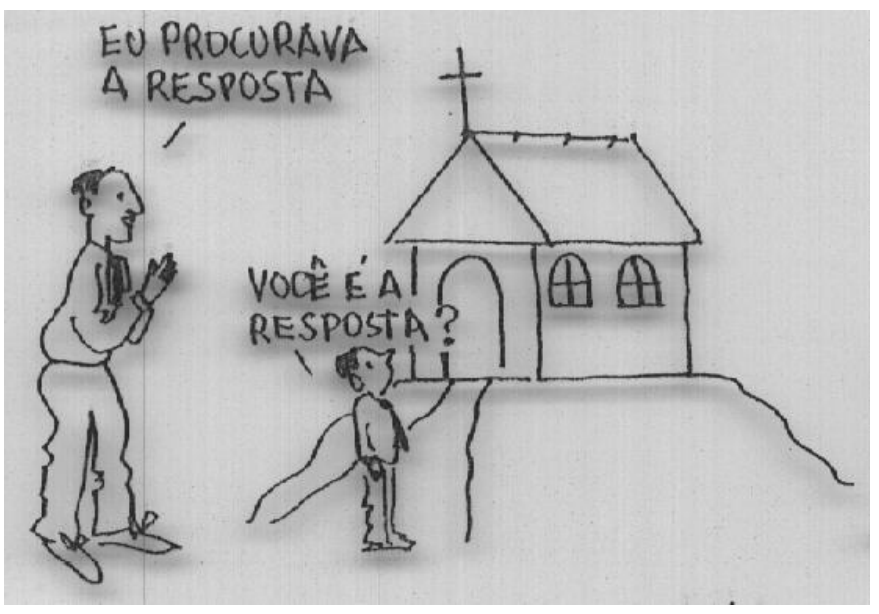

Eu estava inconsciente de que tudo o que fazia era para obter uma resposta convincente a respeito da minha própria existência humana. Vivia sem sequer perceber o que estava para acontecer. Ora buscava na ciência; ora acreditava nas possibilidades dos relatos místicos, religiosos, espíritas e outros mais. O meu "barco da vida" navegava, geralmente, no mar da cultura e impulsionado pelo vento das ideologias persuasivas.

Tudo que precisava fazer era acreditar na viagem sem questionar. O mal-estar da viagem fazia parte do balanço das ondas de sucesso e fracasso; dor e alegria; felicidade e tristeza; razão e fé. A viagem ainda não tinha um objetivo claro definido. Muitas das vezes, a tempestade de "alto mar" fazia com que o barco se mostrasse inseguro. Mas, as tormentas passavam e a vida continuava.

Até que um dia, tudo começou a clarear e a "viagem" começou a ficar mais visível em seus propósitos e fronteiras existenciais. E tudo "começou" - mesmo! - em julho de 1988. Naquela época, eu era um estudante de mestrado da COPPE/UFRJ (Universidade Federal do Rio de Janeiro) e havia sido convidado para participar de uma reunião técnica-científica no sentido de aproximar à universidade (COPPE/UFRJ) dos projetos que estavam sendo realizados na empresa COBRA COMPUTADORES. E nessa reunião tudo aconteceu de maravilhoso e inédito. E tão inédito que até hoje não consegui codificar completamente o fenômeno que vivenciei e continuo vivenciando ainda. O que eu descobri se aproxima da vivência de Cristo-Jesus e dos grandes mestres espirituais tanto do ocidente quanto do oriente.

Assim sendo, é bom relembrar aquela reunião em que se deu a tomada de consciência que descortinou um universo jamais imaginado por mim de sua existência. Era uma reunião normal numa tarde comum e havia naquela reunião umas sete a oito pessoas no máximo. Além do diretor técnico da empresa COBRA COMPUTADORES (RJ), estavam alguns professores, inclusive o meu orientador de tese, e alguns alunos de mestrado. A reunião começou com um professor fazendo as apresentações e agradecendo a presença do simpático e alegre diretor Antônio Paulo (AP). Tudo ia bem, quando eu pedi a palavra e comecei a argumentar com eloquência e segurança. O meu tema era sofisticado (Gerenciamento de 
Configurações, um importante ramo da automação industrial (CIM)). Eu falava com certa facilidade e orgulho, mostrando os problemas inerentes ao processo industrial baseado na microeletrônica e informática avançada. Eu sentia a platéia presente muito atenta e interessada na minha fala e visão. Foi aí que "alguém sobrenatural", que não era esperado, me interrompe interiormente e inicia um diálogo silencioso. Eu fiquei surpreso e confuso. Eu não sabia se continuava falando para a platéia ou se ouvia a "voz interior" me informando de uma condição existencial. A voz interior me dizia que eu estava orgulhoso, acelerado e desequilibrando a minha relação com Ela.

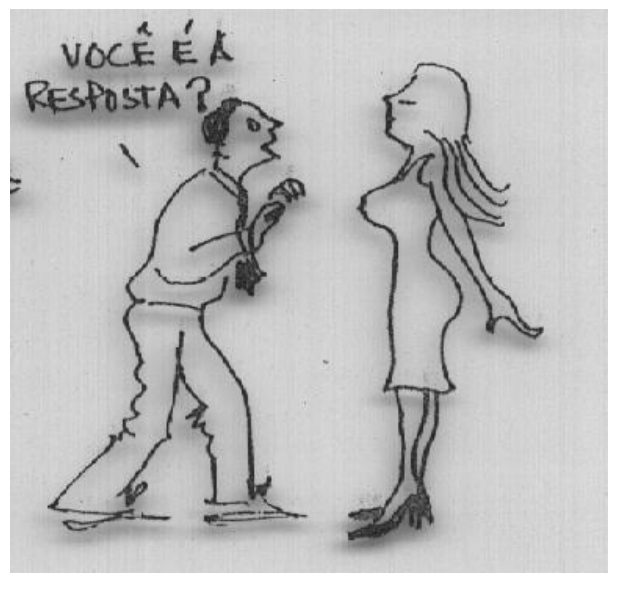

Naquele exato instante de tomada de consciência, percebi que minha realidade na verdade era constituída de uma dualidade, ou melhor, uma polaridade existencial: eu e EU (ou Eu-Nós). De modo que, terminada a reunião eu estava em crise e chorando silenciosamente. Eu não sabia quem era eu (e EU-Nós). Caminhei sozinho, em crise, pelos corredores da universidade da UFRJ perguntando e chorando: "quem sou eu (ou EU-Nós)?".

Após dez dias de intenso e ininterrupto conflito de identidade ajoelhei-me, em prantos, de frente a um quadro de Cristo preso à parede, e roguei com imensa compaixão por mim e pela humanidade: "Pai me dê a verdade. Eu não sei mais o que é a realidade. Pai me dê o conhecimento. Eu não quero o poder. Pai me mostre o caminho da Luz".

Repeti o mesmo gesto e pedido no dia seguinte. E por surpresa minha na noite desse mesmo dia, um sonho que depois veio se repetir por dez dias consecutivos, mostrou-me a pista do caminho da Luz e do Amor de Deus. O sonho se apresentava com um cenário onde aparecia uma mulher vestida de noiva dizendo que eu devia encontrá-la para obter a resposta (a verdade) que eu precisava. E foi a partir dessa busca e investigação que descobri o ponto de partida do caminho existencial - uma realidade mágica, encantadora, inimaginável e indizível.

Logo em seguida saí em campo numa primeira pesquisa exploratória conversando com algumas pessoas mais experientes e em paralelo fazendo leituras em revistas e livros, a fim delinear o significado daqueles sonhos. Imaginei ou especulei que a noiva era um sinal ou simbolismo para que eu procurasse ouvir e prestar atenção na minha própria contraparte tão presente e ao mesmo tempo tão oculta. A noiva poderia ser a minha própria intuição! Feito a suposição, o passo seguinte foi operacionalizar essa suposição, ou seja, testar e confirmar a 
minha hipótese. E para confirmar a hipótese precisei testar o fenômeno da intuição. E como testar a intuição, se misturada a ela estava a razão falante (tagarela!)?

As situações e fenômenos foram acontecendo - não por acaso - de modo que fui levado por uma pessoa mística para conhecer certos lugares que trabalhavam com as esferas espirituais. E foi num lugar desses (PONTE PARA A LIBERDADE no Rio e Janeiro) que encontrei os instrumentos de "coleta e seleção" de dados necessários para perceber a diferença entre razão e intuição.

Assim, usando as técnicas (não-dedutivas e não-indutivas) recomendadas pela PONTE PARA A LIBERDADE (um movimento místico-esotérico) fiz as coletas e interpretações de dados. E ao final do processo isolei a intuição da razão (e distingui a diferença entre idéia e energia). De modo que, feito esse isolamento do "objeto" razão, adquiri um certo poder de auto-observação e identificação (sujeito-realidade e objeto-criado) de mim mesmo. Os sintomas que pude perceber eram de paz, alegria, felicidade (incondicional), serenidade, tranquilidade, fraternidade, bondade, etc.

A busca implacável e solitária transcorria normalmente, até que num belo dia - numa Quarta-feira do mês de agosto de 1988 - o meu processo de auto-descoberta teve o seu momento de glória. Foi numa conversa telefônica com uma colega de pesquisa da COPPE/UFRJ. Eu estava conversando com essa amiga (Gláucia) a respeito da minha ausência, de quase um mês, das aulas na COPPE/UFRJ.

Em dado momento da nossa conversa, onde eu estava contando a minha história de forma doce e amável, aconteceu em meu peito o fenômeno mais fantástico e agradável que um homem, segundo a minha vivência humana, possa vivenciar na face da terra.

A voz interior ordenou-me, após um momento em que tentei negar o meu choro natural: "solte a emoção" Era uma ordem superior para liberar-me e assim experimentar o mais incrível e maravilhoso de todos os fenômenos: o Amor Cósmico Divino no "coração" (chakra cardíaco).

Naquele instante, o meu peito "implodiu" num doce êxtase Divino. Em seguida, desliguei o telefone e percebi um raio cósmico saindo do centro da palma da mão esquerda. Era um raio cósmico invisível, mas concentrado e sensível ao contato direto nos olhos e na pele. Fui orientado, intuitivamente, para sentar sobre os meus calcanhares.

Nessa posição sentado recebi orientação interna para fechar a mão direita em forma de concha. O que aconteceu? Constatei sensivelmente a presença de raios cósmicos divinos que chegavam - vibrando! - em grande quantidade e intensidade do cosmo. E penetravam nas pontas dos meus dedos (exatamente nas impressões digitais) e alteravam a freqüência 
(vibração) do "chakra cardíaco" (os "chakras são muito estudados pelas práticas iogues, reikianas etc).

O meu êxtase - que já era estupidamente grande! - aumentava mais ainda quando captava, através das pontas dos dedos das mãos, esses raios cósmicos divinos. Eu chamo esse fenômeno de AMOR DE DEUS. Os orientais denominam essa experiência pessoal de SAMADHI ou NIRVANA e Jesus denominava esse estado de consciência de BEMAVENTURANÇA (e AMOR).

Várias experiências e fenômenos contribuíram, alguns dias depois, com beleza e sutileza me deixando mais e mais perplexo. Um dia após a experiência sagrada do Amor Incondicional fui prestar um serviço espiritual num centro místico-espiritual que freqüentava (recentemente) como médium às quintas-feiras, localizado em Ipanema (Rio de Janeiro). Uma semana após, recebi o comunicado que nesse dia (em que trabalhei com um raio fino saindo da minha mão esquerda) houve uma cura milagrosa nesse centro místico-espiritual.

Nesse período, senti exalar do meu hálito e das plantas um perfume extremamente doce e gostoso. As minhas roupas ficavam impregnadas por esse perfume e o meu pequeno apartamento também. Creio que o fenômeno do perfume é conseqüência de um processo de "purificação" ou "alquimia" do ser. Foram momentos de extrema beleza e sacralidade. Momentos que marcaram profundamente a minha maneira de ser.

Um ditado popular diz que "O Amor marca as pessoas". A minha mão diz para mim que sim. A experiência do Amor de Deus marca o ser humano. Além de marcar Ele liberta positivamente. Se não libertar o ser humano não é o verdadeiro Amor Dele. Amor e liberdade caminham juntos. Hoje, não acredito mais no amor que aprisiona os indivíduos uns aos outros. Não, não creio mais nisso. O verdadeiro Amor liberta sempre. Ele eleva. Glorifica. Aproxima. E une, sem prender, o ser humano à energia sutil do Amor. Ele é pura energia: LUZ! Nesse contexto:

O homem é um ponto de luz divina, envolto por numerosos envoltórios, como uma luz escondida numa lantera. Esta lanterna pode ser fechada e escura, ou aberta e radiante. Tanto pode ser uma luz brilhante diante dos olhos dos homens, como uma coisa oculta, sem utilidade para os demais. (BAILEY, 1984)

Hoje, a maioria se pergunta: qual é o sentido da busca? O que buscamos? O que devemos fazer para melhorar o atual nível de evolução com qualidade de vida? E de visão de mundo? Qual é a luz que falta nos iluminar? 
É no exercício da mente que está o nó da questão. A mente humana é aparentemente um instrumento que pode ser empregado em duas direções. Uma é para o exterior: A mente, ao funcionar neste modo, registra os nossos contactos com o mundo físico e o mundo mental em que vivemos, e reconhece as condições emotivas e sensoriais. É o registrador e o que correlaciona as nossas sensações, reações e tudo o que lhe é transmitido por intermédio dos cinco sentidos e do cérebro. É um campo de conhecimento que foi largamente estudado e os psicólogos fizeram grandes avanços na compreensão dos processos de mentalização. "Pensar", diz-nos o Dr.Jung, "é uma das quatro funções psicológicas básicas. É esta função psicológica que, de acordo com as suas próprias leis, modela as representações dadas em suas conexões conceituais. É uma atividade perceptiva, tanto passiva como ativa. O pensamento ativo é um ato de vontade, o pensamento passivo uma ocorrência.

Como veremos mais tarde, é o aparelho do pensamento que está envolvido na meditação e que deve ser treinado para acrescentar a esta primeira função da mente a capacidade de se voltar para outra direção, e de registrar com igual facilidade o mundo interno e intangível. Esta habilidade para reorientar-se permitirá à mente registrar o mundo das realidades subjetivas, das percepções intuitivas e das idéias abstratas.

O problema que hoje se põe para a família humana, no domínio da ciência e da religião, resulta do fato que o seguidor de uma e de outra descobre se encontrar no limiar dum mundo metafísico" (BAILEY, 1984, p.14-15).

A busca da evolução da qualidade de vida é o esforço de reencontrar o sentido da perfeição de todas as coisas essenciais manifestadas e até mesmo "imanifestadas". Esse esforço persistente e incansável dá o tom e o valor da descoberta. E o valor novamente submetido a novo esforço se autoeleva, se autovaloriza. Esse autovalor é a Luz resultante do ganho de energia na subida, no crescimento e no salto. Daí, a qualificação natural, o sentido exato, preciso da evolução: luz, energia, vigor, força, vontade, inteligência, sensibilidade, intuição e, portanto, Amor Cósmico. Consciência Cósmica. Ser Humano evoluído. Ser Humano holístico. Ser Humano qualificado. Completo. Iluminado. E seguro. Amante da natureza. Amante de todos de forma incondicional. Ser-espelho de consciência de Deus-Pai.

A direção certa, não é aquela de seguir cegamente, mas seguir na direção de uma orientação de um impulso natural, com ritmo natural proveniente de uma fonte original imutável. Seguir por apenas seguir, é ilusão. É insegurança e medo. É aceitação cega de idéias não comprovadas, não verificadas por nós mesmos. É seguir copiando. 
Precisamos ser a própria origem das coisas que nos acontecem. E também ser a fonte do saber e da sensibilidade em ser. Ninguém gosta de ser resto, lixo ou sobra. Não acredito que viemos viver na Terra para competirmos entre nós e em consequência disso alcançarmos uma vida miserável, infrutífera, decadente e desqualificada (para muitos "não eleitos" ou "ignorantes"). Não! Sinceramente não acredito mais nisso. Não acredito nessa "normalidade". Isso tudo, é sintoma de um grande desvio. Desvio esse originado pela cultura que realizamos desde as civilizações muito antigas.

A natureza de Deus é implacavelmente perfeita no governo de seus princípios. Nada acontece por acaso. Tudo tem uma causa, uma origem.

A evolução requer perfeição no domínio dos princípios que governam a natureza, inclusive, a nossa própria natureza humana. A natureza de Deus-Pai é tão perfeita que para descobri-la ou vê-la precisamos antes de tudo nos capacitarmos para o seu (de Deus) nível de visão e compreensão. Isto porque ELE (Deus) é o princípio de hierarquia, de evolução, de qualidade, de sintonia e de equilíbrio.

Nesse sentido, como analogia, não podemos equilibrar um grão de arroz com uma tonelada de ferro. Um frigorífico gelado com o calor de uma ponta de cigarro. A inteligência de Einstein com a ignorância de um indivíduo não intuitivo. A sensibilidade supra-objetiva de Buda com a insensibilidade de uma "fera-humana" criminosa e violenta. O Amor de Jesus Cristo com a carência afetiva do desejo sexual de uma pessoa comum.

A descoberta da perfeição exige de antemão que sejamos perfeitos. Isto porque a imperfeição não consegue ver a perfeição. $O$ desequilíbrio não consegue perceber o movimento de equilíbrio. O menos complexo não consegue abranger o mais complexo. A incerteza não consegue determinar a fé. A paixão não consegue sentir o Amor sublime. $\mathrm{O}$ desejo não consegue agir com vontade. $\mathrm{O}$ inferior não consegue sem disciplina vivenciar o que lhe é superior. Nesse contexto, o ignorante não consegue entender o universo do intelectual. E tampouco o intelectual consegue entender o universo do homem-santo. E como consequência surge o sentido de evolução e transformação. E esse sentido se dá através da força de mudança que cada um imprime em sua própria natureza humana. Esse sentido é ao mesmo tempo um grande paradoxo e um grande mistério da evolução ontológica (suprapsicológica) em todos os tempos.

A menor distância entre dois pontos é a nossa própria evolução ontológica. 


\section{Referências:}

BAILEY, Alice A. Do Intelecto à Intuição, Niterói-RJ: Fundação Cultural Avatar, 1984, trad.: Fundação Cultural Avatar, From Intellect to Intuition, $\quad$ Londres, Lucis Trust, 1972.

MELGAÇO DA SILVA, Bernardo \& GURGEL, Verônica Monaliza Gomes. A Divisão e a Especialização do Trabalho e a Emergente Abordagem Inter-Transdisciplinar e Holística da Saúde nos Serviços Pediátricos dos Hospitais do Cariri Cearense. Projeto de Iniciação Científica, 2006.

MELGAÇO DA SILVA, Bernardo. Trabalho e Transformação: A Organização da Produção e o Nível de Consciência nas Sociedades Modernas, Rio de Janeiro, COPPE/UFRJ, Tese de Mestrado, 1992.

A força do trabalho humano e as suas dimensões ética, estética e técnica nas culturas moderna e tradicional, Rio de Janeiro, COPPE/UFRJ, Tese de Doutorado, 1998

Sobre o autor:

(1) Bernardo Melgaço da Silva é Doutor pela Universidade Federal do Rio de Janeiro e Professor da Universidade Regional do Cariri - URCA. Crato-CE.

E-mail: bernardomelgaco@hotmail.com

Como citar este artigo (Formato ISO):

SILVA, Bernardo M. Relato de uma crise-experiência interior: uma vivência mística-ontológica. Id on Line Revista de Psicologia - Edição Especial Educação e Saúde, set. 2009, vol.1, no.9, p.15-22. ISSN 1981-1189. 